\title{
'Un viejo que leía novelas del boom': natura, cultura y maravilla en Luis Sepúlveda
}

\section{'The Old Man who Read Boom Stories': Nature, Culture and Wonder in Luis Sepúlveda}

\author{
GABRIELE BIZZARRI \\ Università di Padova
}

Palabras clave

natura; cultura; maravilla; estudios postcoloniales; identidad; bestseller; global/local.

El artículo se propone demostrar cómo en la delgada trama de la 'novelita global' que le valió a Luis Sepúlveda el primero de sus muchos éxitos editoriales se dan cita -remezclándose, compactándose, a veces, banalizándose en una pulpa pensada, con toda evidencia, para el mercado- los ecos de la gran tradición narrativa hispanoamericana del siglo XX, la que, buscando o construyendo una identidad propia, emancipada, por fin, de los modelos coloniales, se concentra en matizar las fronteras que separan y oponen el Viejo y el Nuevo Mundo, la civilización y la barbarie, procurando trastornar, en general, la validez de toda categoría fija y disturbando, muy especialmente, la contraposición excluyente, definitoria dentro de la episteme occidental, que gestiona la relación realidad/irrealidad. Al reanudar esa gloriosa tradición, el escritor chileno consigue el nada despreciable efecto de crear una oportuna discrasia dentro del contexto de la 'literatura hispanoamericana globalizada' que domina en la década de los Noventa.

The article aims to study how in the thin plot of the 'global shortnovel' that earned Luis Sepúlveda the first of his many editorial successes a number of textual echoes linger and intertwine, remixing and compacting themselves in a seductive pulp designed, with

Keywords

nature; culture; wonder; postcolonial studies; identity; bestseller; local/global. all evidence, for the market. In particular, the reader can track each one of the different segments of that great Twentieth Century Spanish-American narrative tradition whose main goal was the research or the construction of a local identity finally emancipated from colonial models, a prodigious series that strategically focused on blurring the boundaries that separate 'civilization' from 'barbarism', the Old from the New World, dismantling, in general, the validity of every fixed category, and disturbing, in particular, the exclusionary opposition that, in the Western episteme, regulates the 'reality/unreality' relationship. By resuming this glorious path, the Chilean writer achieves the not insignificant effect of creating a timely laceration in the continuum of the 'globalized HispanicAmerican literature' that dominates in the 1990s. 
En 1993, un hasta aquel entonces casi desconocido periodista chileno publica en España, para un sello importante como Tusquets, una novela breve, empapada en humores ecológicos y etnográficos, que cuenta como uno de los últimos grandes 'best-sellers periféricos' (por lo menos por lo que a Latinoamérica se refiere): Un viejo que leía novelas de amor de Luis Sepúlveda traducida a sesenta idiomas, con más de 18 millones de ejemplares vendidos- se convierte inmediatamente en un caso editorial sin precedentes, sobre todo para una obra que uno de los escasos comentaristas académicos que de ella se han ocupado -nada casualmente, me parece, cruzando lo literario con lo pedagógico y lo antropológico- considera cercana a la oralitura y el etnotexto (Malaver Rodríguez, 2001), aparentemente escrita desde un paradigma otro, con el intento de defender la des-homogeneidad amenazada del contexto selvático.

En realidad, sí se podría invocar un precedente bastante directo, en cuya estela el relato ejemplarmente exótico de Sepúlveda, más o menos conscientemente, se pondría: me refiero al clásico de los clásicos de la modernidad narrativa hispanoamericana, Cien años de soledad de Gabriel García Márquez, el verdadero eje de un canon que, justo a su alrededor, hacia mediados de los años Sesenta del siglo pasado, empieza a ponerse en marcha según los patrones indicados por los postcolonial studies.

Válgame entonces el ejemplo, pero eso sí, guardando las debidas proporciones.

No se me escapa, en efecto, la sospecha de lo para-literario, el riesgo de la simplificación que supone el hecho de trabajar con un texto que parece estar pensado más para la divulgación y desde lo político -como un panfleto, a la vez ecologista e indigenista- que desde una poética o un estilo propios. Para más señas, la novela en cuestión se expresa, tanto por lo que se refiere a la lengua utilizada como a las formas de la narración, mediante el argot universal, transfronterizo y últimamente homogéneo del 'género' de los superventas que, hecho totalmente paradójico en el caso de un escritor que aspira a hacerse vocero de ciertas marginalidades supervivientes, según estudiosos como Ercolino (2015) y Calabrese (2015), tiende al maximalismo y a la globalidad, escondiendo lo más propiamente local e intentando hablar desde el intersticio de la transacción (económicamente) necesaria entre diferentes sistemas y tradiciones.

Sin embargo, podría resultar provechoso leer a Sepúlveda precisamente desde la herida abierta por sus ambigüedades, hilos colgantes y tensiones irresueltas: lo que me propongo hacer aquí, de hecho, es estudiar la novela en cuanto fenómeno sociocultural, insertándola en una línea de continuidad explícita -que en algunos casos llega a rozar el plagio- con respecto a la gran tradición narrativa hispanoamericana del siglo XX, dando así cuenta de una operación, quizás, escasamente original o poco 'autoral', pero, como veremos, para nada descontada y, en todo caso, sumamente estratégica considerando el contexto en el que se produce. Como veremos, el punto de contacto más evidente tanto de esta opera prima como de las sucesivas entradas de la ingente bibliografía de este exiliado chileno con el legado literario más característico de todo un Continente-allí donde Sepúlveda reanuda unas prácticas y visiones por lo menos parcialmente truncadas, volviendo a sacarle brillo a ciertos trucos y artimañas que, después del uso masivo y del abuso consumista, parecían exhaustos (como si de juguetes inéditos se tratara, listos para embaucar a una nueva generación de compradores olvidadizos) ${ }^{1}$-, es la problematización -típicamente latinoamericana, incluso 'latinoamericanista'- de los códigos

\footnotetext{
${ }^{1}$ Véase al respecto el brillante artículo de Eduardo Becerra (2008), cuyo título -que habrá que leer dirigido al modo mágico-realista prevalente en muchos clásicos de l'âge d'or de las letras del Subcontinente- es de por sí todo un programa: "¿Qué hacemos con el abuelo?".
} 
que establecen las fronteras entre los tres mundos posibles, y sólo aparentemente inamovibles, de 'natura', 'cultura' y 'maravilla'.

El título de mi artículo pretende señalarlo, hasta con cierta malicia.

En Un viejo que leía novelas de amor de Sepúlveda cuesta escuchar una voz, y más bien resuenan, sintonizados en una frecuencia pensada para ser captada por un público masivo, los ecos de muchas voces: las de los paladines del panteón literario hispanoamericano, de Alejo Carpentier al Vargas Llosa de La casa verde, pasando por el Gabo y remontándose hasta las tradiciones temprano-novecentistas de la novela de la selva y el indigenismo literario; en otras palabras, las estaciones más notorias del vía crucis de un discurso cultural que pugna por reconocerse propiamente americano alrededor de algunos temas y, sobre todo, lugares tópicos. Es con esos ingredientes que Sepúlveda enciende los fuegos de su sabrosa cocina narrativa, amalgamándolos todos en un amasijo, otra vez, bastante homogéneo y oportunamente aderezado-no falto de cierta visionaria eficacia y brillo narrativo-, además de fácilmente digerible, totalmente apto para los delicados estómagos de los 'turistas de la otredad'2.

Evocando, como en una ideal sesión de espiritismo, los fantasmas textuales más reconocibles de la que definiré la gran literatura de la diferencia, Sepúlveda consigue que vuelvan a brillar las grandes imágenes de referencia del repertorio latinoamericano, las que nacieron para servir de ideal soporte al que constituye el macro-tema de la(s) literatura(s) postcolonial(es) -el de la búsqueda (o construcción) de una identidad propia-, imágenes, entonces, indefectiblemente locales, concebidas como sanación posible de la herida impuesta por la Conquista, que empiezan a circular, con sordina, desde la propia Colonia, para luego ir perfeccionándose durante la época de la Independencia política, y literalmente culminar, hacia mediados del siglo pasado, en un verdadero boom editorial, el 'fenómeno' por antonomasia de las literaturas hispanoamericanas: me refiero a esa aventajada promoción de escritores que se fue convirtiendo -como veremos, algo problemáticamente- en un sello de reconocimiento, dándole un rostro familiar, para el lector occidental, a una América de las letras hasta aquel entonces totalmente desconocida, y transformando, de hecho, Macondo -el pueblo imaginario perdido en la lejanía de la selva tropical, fuera de la Historia y, en cambio, hundido hasta la médula en las sabidurías mágicas y ancestrales de los pueblos indígenas (léase también: el pueblo inventado por García Márquez para ser metáfora o metonimia de un único, inmenso Continente solitario ${ }^{3}$ - en un verdadero brand, y con él, Cien años de soledad en un improbable clásico de aeropuerto.

Como decía, la primera novela de Sepúlveda supone un restablecimiento de esa línea, que es, de hecho, por aquel entonces, una línea sino del todo truncada, por lo menos una que ha ido deshilachándose más y más: mediante su llegada en el mercado editorial internacional, el escritor chileno está defendiendo la naturaleza política de esas imágenes de referencia; es decir, desde lo literario, se vuelve a apostar por un proyecto Latinoamérica idealista y revolucionario que, también por el efecto-rebote provocado por este 'clásico' de la edad del bronce, por este manual latinoamericanista para principiantes, se recoloca estratégicamente como propuesta viable en beneficio de una época de globalizaciones desenfrenadas y devoradoras.

\footnotetext{
2 Definiría el modo de trabajar de Sepúlveda típicamente postmodernista (muy a pesar suyo, me temo): de hecho, tomo prestada la imagen de la cocina, del sampling de ingredientes culturales diferentes -remezclados de la forma más higiénica posible para los entusiastas más delicados de la fusión- del libro en el que Remo Ceserani (1997) trata de dar cuenta, justamente, de los rasgos más característicos de la experiencia estética de la postmodernidad.

${ }^{3}$ Véase al respecto Oviedo (1969).
} 
Reformulando, por entre las líneas de esta novelita global, se asoma una idea de América, una que tiene que ver con una opción cultural resistente y des-homogénea encarnada y localizada en el Nuevo Mundo, según una visión, de hecho, nada nueva sino muy coherente con las que serían las pautas tradicionales de la representación literaria de la autoctonía americana, pero que, en realidad, cuando Un viejo que leía novelas de amor empieza a circular, ya se había vuelto bastante minoritaria.

Trataré entonces de hacer dos cosas: por un lado, demostrar la deuda de Sepúlveda para con esa tradición que, de cauce mayoritario de las letras locales, se ha ido convirtiendo en un objeto caduco, quedando marginalizada por un afán parricida y un deseo de desprovincialización que han provocado la dispersión de las marcas de la especificidad cultural en la altamar de la literatura global (Montoya Juárez \& Estéban, 2008; Volpi, 2009; Aínsa, 2012) y por otro, propondré una reflexión acerca de la oportunidad -o, mejor dicho, la urgencia- de un gesto, estética y culturalmente, tan demodé.

\section{Novela y territorio: de la cartografía de la diferencia al mapamundi de la uniformidad}

En diálogo con la proliferante bibliografía crítica que ha tratado de mapear el fenómeno ${ }^{4}$, diré que los rasgos más destacados -y también los principales ingredientes del éxito-de la generación del boom podrían reducirse a dos: 1) en una época caracterizada, por lo menos de este lado del mundo, por un generalizado cansancio de la narración, esos novelistas apostaron por el puro gusto de la fabulación, la vuelta al placer del relato, contaminando, además, la tradición novelesca occidental mediante el recurso al mito, al folclor, a la oralidad de los cuentacuentos indígenas... y, de hecho, embistiendo al lector occidental, cansado de cerebralismos formales y experimentaciones con la textualidad que se enrosca, la palabra que abdica al intento de aprehender la cosa, con una formidable explosión pirotécnica de sabiduría narrativa, convocándole a sentarse idealmente alrededor del fuego de una sociabilidad comunitaria del todo perdida; 2) además -como decíamos antes-, en todas esas novelas, asistimos a una concentración altísima de tipos humanos, situaciones y, crucialmente, paisajes indefectiblemente locales, característicos del que, desde dentro de ese paradigma en construcción, Alejo Carpentier llamaba El reino de este mundo. En otras palabras, estas narraciones manifiestan una pronunciadísima tendencia cartográfica, pugnan por hacerse mapas de una experiencia irrepetible arraigada en el territorio, luchan por reconquistar, a golpes de imaginación, una geografía enajenada, marcando así las pautas de un gusto que, desde otro punto de vista, se presta también a satisfacer los apetitos orientalistas ${ }^{5}$ del consumidor occidental, interceptando una demanda del mercado: proponiéndose narrar un continente, las novelas del boom, en cierto sentido, si las miramos desde la sociología de la lectura, funcionan también como libros de viaje (o 'guías turísticas').

En la novela de Sepúlveda encontramos ambos aspectos.

Ante todo, el pueblo imaginario que -por cierto, bastante ambiguamente- lleva el nombre de "El Idilio" restablece la tradición de las ciudades identitarias, los territorios inventados (muy señaladamente) por los escritores del boom para concentrar los rasgos definitorios del hombre americano, que ha heredado de la Colonia una angustiosa crisis de presencia. La reivindicación

\footnotetext{
${ }^{4}$ Además del estudio 'desde dentro' de Carlos Fuentes (1969), véase al respecto, entre otros, Aínsa (1986), Campra (1998) y Ortega (1998). También puede interesar el breve artículo de Tatiana Bensa (2005).

${ }^{5} \mathrm{Ni}$ hace falta mencionar el fundamental ensayo de Edward Said (2003).
} 
de una identidad propia, como señala entre otros Rössner (1997), pasa, en muchos casos, por la ensoñación palingenética y el viaje a la semilla, por la voluntad de refundar la inocencia natural perdida con la llegada de la Historia y el descubrimiento. Realmente, en este sentido, a raíz de la publicación de la obra maestra de Gabriel García Márquez, todos los latinoamericanos pasan a ser ciudadanos de Macondo (Vargas Llosa, 1971), es decir, se reconocen en un proyecto identitario primitivista, vinculado con la utopía regenerativa de los lugares, con el aislamiento encantado de una naturaleza "anterior al pecado original" (García Márquez, 1996: 94) y, obviamente, con la expulsión del Paraíso. Sin embargo, en consideración de la profunda mutación de la atmósfera cultural del fin del siglo, habrá que ver hasta qué punto el lector (hispanoamericano) de Sepúlveda, después de tanta agua pasada por ese "río de aguas diáfanas" y "piedras pulidas" ahora más bien 'turbio', se sienta todavía representado por ese proyecto, si esté todavía disponible a dejarse llevar a habitar de vuelta en el medio de la selva ancestral. O si más bien, como dejarían entender los rumbos de la literatura más contemporánea, no haya decidido -de una vez- ser uno mismo con el mundo, vivir, más o menos integradamente, en la aldea global, pisando los restaurantes y cafeterías que esterilizan el panorama de las diferentes megalópolis latinas, disfrazadas ya de comunes sucursales del Imperio.

Además, igual de importante, la novela de Sepúlveda se abre con una dedicatoria al alcalde indígena de la localidad de Sumbi, "gran defensor de la Amazonía", en última instancia, el verdadero responsable del relato que, "en una noche de narraciones desbordantes de magia", como en una ceremonia de iniciación, le confía al autor "algunos detalles de su desconocido mundo verde, los que más tarde [...] me servirían para construir esta historia” (Sepúlveda, 1993: 6). Aquí se vuelve hecho literal, hasta se banaliza por exceso de explicitación -poniendo en entredicho incluso la 'autoría' del texto-, la tendencia, típica de toda esa generación, a convertir el palimpsesto cosmogónico indígena en un caudal de fuentes profundas y ocultas.

Este tipo de literatura, como decíamos, llega, a principios de los Noventa, a un punto sin retorno. Por muchos lados, se empieza a señalar el riesgo del exotismo y del cliché (naturaleza virgen, folclor, animismo, prominencia del componente indígena...: un verdadero baratillo de gustosas 'excentricidades') y se pretende apagarle el aura a esta América recién nacida cual sujeto culturalmente emergente (Volpi, 2009), para intentar representarla, finalmente, como parte integral dentro de un contexto universal y que aspira, cada vez más, a uniformarse. La hispanoamericana de los Noventa - como ya no, en cambio, la de las últimas dos décadas- es literatura "sin fronteras" (Noguerol, 2008), que pretende confundir toda marca geográfica, quebrar el doble vínculo que, tradicionalmente, la tiene atada con los espacios periféricos de la naturaleza americana (y su insufrible mitología), romper la cáscara del huevo y salir corriendo de la soledad de Macondo para habitar la aldea global e inventar, así, otro espectáculo -otro simulacro-, igual y contrario, pero mucho más peligroso: la puesta en escena de un Subcontinente metropolitano, furiosamente urbanizado, según supone la llamada a las armas del 'manifiesto' $\mathrm{McO}_{c}$ ndista ${ }^{6}$. Como saben los lectores del afortunado prólogo de la antología narrativa publicada en 1990 por los chilenos Alberto Fuguet y Sergio Gómez, sustituyendo "los árboles de la selva" con "rascacielos", retorciendo el inexplicable eco sobrenatural del nombre de la ciudad de los Buendía para que intercepte el de los sellos multinacionales más cotizados con la invención de un 'Macondo Incorporated'-, se pretendía dar cuenta de la mera realidad de

\footnotetext{
${ }^{6}$ Sobre el uso -más o menos instrumental- del elemento urbano en los relatos más notables de la antología, véase Fava (2012). Sobre la mistificación política - de cuño neoliberal- que estaría a la base de la construcción de la nueva 'realidad' latinoamericana defendida en el prólogo que los precede, cfr. Palaversich (2005).
} 
un territorio que, muy lejos de seguir siendo la tierra de conquista para cualquier aventura de la imaginación desaforada, la tierra de las mil y una utopías, finalmente, se habría convertido en un lugar más, donde, por ejemplo, "si la gente vuela es porque anda en avión o están muy drogados” (Fuguet \& Gómez, 1996: 15). Citando al poeta chileno Oscar Hahn, los animadores del proyecto $\mathrm{McO}$ ndo reducen el realismo mágico - una de las patentes más notorias del latinoamericanismo literario, la firma estilística del "arcángel San Gabriel”, el ídolo por derrocar- a un espectacular fraude, un caso flagrante de embaucamiento de incapaces, rebajando la significancia identitaria de sus 'maravillas naturalizadas' -esa reapropiación de las sabidurías prehispánicas sepultadas y, sin embargo, todavía al acecho en los espacios de la alteridad selvática $-\mathrm{y}$ tratando sus artimañas como charlatanerías de feria:

Cuando en 1492 Cristóbal Colón desembarcó en tierras de América fue recibido con gran alborozo y veneración por los isleños, que creyeron ver en él a un enviado celestial. Realizados los ritos de posesión en nombre de Dios y de la corona española, procedió a congraciarse con los indígenas, repartiéndoles vidrios de colores para su solaz y deslumbramiento. Casi quinientos años después, los descendientes de esos remotos americanos decidieron retribuir la gentileza del Almirante y entregaron al público internacional otros vidrios de colores para su solaz y deslumbramiento: el realismo mágico. (16)

No hay que olvidar entonces que es con este telón de fondo que Sepúlveda nos vuelve a hundir en la región salvaje, en territorio indígena, en el corazón de la Amazonía, volviendo a encontrar, para decirlo de alguna manera, el camino de vuelta a Macondo desandando los pasos perdidos y, así, volviendo también a abrir la herida de un enfrentamiento cultural -el del centro y la periferia- que, por ese entonces, se estaba pretendiendo cerrar de manera precipitada y arbitraria.

De hecho, como iremos viendo, la selva sepulvediana, poblándose de infinitos ecos y resonancias hondamente vinculados con la compleja elaboración del trauma colonial incluyendo también los de la desmaterialización y el desencantamiento-, es todo menos un espacio diputado a replicar el engaño de lo 'natural' y se convierte más bien en un crucial laboratorio de experimentación identitaria, una frontera móvil alrededor de la que cultura y natura vuelven a negociar -reconsideran de modo incesante y sintomáticamente posibilista en estas periferias remotas de la episteme occidental- sus respectivos ámbitos de competencia, aprovechando todas las posibilidades de una productiva y sintomática inestabilidad de lo 'real'.

En efecto, la novela de Sepúlveda nos invita a activar un sistema de identificaciones y correspondencias bastante esquemático para luego matizarlo más y más hasta llegar a invertirlo, llevando al descubierto la convención a partir de la que ordenamos definiciones y aplicamos rótulos categóricos. Un ejemplo: si esta es una novela de la frontera (y la selva es el espacio fronterizo donde llegan -y se pierden- aventureros y colonos), la función del héroe tendría que coincidir con la domesticación del medio hostil, dibujado como una alteridad absoluta y destructora, irreductible para el intelecto humano e insensible a sus razones. Pero en realidad, dándole la vuelta a la perspectiva antropocéntrica mediante un ejercicio de inmersión en el pensamiento salvaje propiciado por el vistoso proceso de humanización de la bestia, Sepúlveda deslegitima la lectura paradigmática del paisaje. Por otro lado, ni siquiera el otro polo, el de la civilización, vaciándose de todo heroísmo y quedando asociado con rasgos, o bien violentos, o ridículos, sabe contestar oportunamente a los estímulos del código. De hecho, ninguno de los 
dos representantes de los dos órdenes simbólicos llamados a enfrentarse de acuerdo con las dinámicas de la trama -el hombre y el animal, el cazador y su presa, el viejo y el tigrillo- logra aprehenderse en categorías claras: ambas son criaturas inciertas, hechas para habitar un espacio intersticial, pensadas para confundir los estereotipos representativos y, finalmente, llegar a encontrarse a medio camino, en un diálogo mortalmente cómplice, justo en el borde de una frontera simbólica todavía por trazar. La pregunta fundamental del texto -lo repito: un punto no exactamente por estrenar, pero que el escritor chileno resitúa amenamente en la que había sido una zona caliente para esta clase de reflexiones y que, en cambio, por motivos poéticos o políticos, la literatura contemporánea se estaba ocupando de 'desembrujar'- es más o menos la siguiente: ¿qué es 'cultura' y qué significa 'natura'?, o mejor, ¿cómo se manejan estos dos polos -qué sentido tiene el viejo cuento de civilización y barbarie- en tierras donde una cultura única, ante la incapacidad de relativizar su propio paradigma generador, ha acabado con todo un ecosistema de culturas ajenas No cabe la ingenuidad en las definiciones y menos aún en lugares donde histórica y antropológicamente se han encontrado y han chocado maneras diferentes de entender la relación entre el hombre y la naturaleza ${ }^{7}$, y donde la sustancia ambiguamente 'natural' de los lugares y de quienes los habitaban proporcionó la coartada ideal para la aculturación forzada y la domesticación del salvaje (Todorov, 2013; Gruzinsky, 1991). En la redefinición del espacio desde donde se traza la línea que separa cultura y natura (norma y excepción, normalidad y aberración...), sobre el cuestionamiento del punto de vista y la necesidad de hacer visible el lugar de la enunciación a partir del que se dictaminan palabras absolutas que suenan a condenas, 'inventan' al subalterno y justifican actos de poder, se juegan, tradicionalmente, todas las grandes batallas de la literatura hispanoamericana que, desde sus raíces, se vincula con la búsqueda de una forma 'propia' de habitar la modernidad, una que aproveche y explote todo el potencial de resistencias(s) implícito en su condición periférica.

Antes de volver a la novela, por tratarse del elemento fundamental de la propuesta tanto narrativa como política de Sepúlveda, me parece importante ir trazando una breve historia portátil de la representación del elemento selvático en las literaturas hispanoamericanas. Adentrémonos, pues, por una paradójica galería de selvas de papeß .

\section{Trampantojos 'naturales': historia portátil de la representación de lo barbárico latinoamericano}

Como decíamos, mimetizados detrás de los miles de rostros cambiantes que componen su muralla verde, realmente al acecho en la selva sepulvediana, junto con el tigrillo desesperado, están las piezas de todo un discurso cultural de la alteridad. El que, de la Colonia en adelante, busca afanosamente alcanzar el beneficio de una mirada autóctona hurgando en los vacíos del discurso oficial, en las soledades del lenguaje, en los puntos ciegos de la contraposición estructuralmente violenta que vertebra -y malogra- el diálogo entre la madre patria y las colonias: citando a José Martí, el gran poeta patriarca de la Independencia cubana, experiencia natural vs libro importado. Merece la pena, sin embargo, introducir un tercer elemento, uno que, por otro lado, circula por el eje de la oposición martiniana como un vicio inherente: el de una naturaleza que, paradójicamente, restituye al ojo del europeo una fuerte impresión 'no natural'

\footnotetext{
${ }^{7}$ No me parece, de hecho, casual que la literatura hispanoamericana 'clásica' se esté convirtiendo actualmente en una verdadera mina por explorar para la ecocrítica.

8 Una buena guía para emprender el viaje es, sin dudas, León de Hazera (1971).
} 
(o sobrenatural), una naturaleza que también tensa otra clasificación, la que encasilla en dos contenedores separados, en este caso, la realidad y la maravilla.

Como se sabe, en los diarios de navegación de Colón y, en general, en las relaciones de viaje y crónicas copiosamente redactadas por los exploradores occidentales, el Nuevo Mundo recién estrenado y, más en concreto, su naturaleza virgen - de la que los nativos no representan más que una entre las muchas asombrosas manifestaciones- aparecen como objetos literalmente increíbles, 'fenómenos' a los que no se hace ningún esfuerzo por aproximarse con la oportuna exactitud científica o mediante una real tensión cognoscitiva, sino más bien, según un mecanismo en el que el rechazo y el apetito explotador son apenas las dos caras de la misma moneda, se procede a convertir en repositorios vacíos a la vez de todos los deseos y los miedos de Occidente: el territorio americano es, entonces, un inverosímil paraíso en tierra listo para la depredación o un inaceptable, endiablado garabato, poblado por toda clase de monstruosidad. En la Historia Verdadera de la Conquista de la Nueva España de Bernal Díaz del Castillo, la "obscena promiscuidad" de la selva tropical, esa plétora insensata de inciertas formas vivas, frutos y animales como recién salidos de un bestiario medieval encarnado, salta literalmente afuera de la actividad del cronista y desborda las posibilidades expresivas del medio que utiliza, excede la jaula de la escritura-documento y rompe las pautas de la observación naturalista; coherentemente con su estatuto de 'cosa de maravilla', queda más bien intuitivamente asociada con los encantamientos del mago Merlín y las brujerías que, en este lado del mundo, sólo podían circular por los libros de caballería. Será este "delirio áureo de nuestros fundadores" -el síntoma más vistoso de la incapacidad del europeo de relativizar culturalmente las fronteras de su propia (versión de la) realidad- el que, según diría García Márquez (2014: 167), inaugurará la novela hispanoamericana moderna.

Siguiendo con el repaso ${ }^{9}$, durante la Colonia se apostó por intentar encorsetar el mundo americano, su alteridad 'natural', importando e imponiendo modelos y pautas ${ }^{10}$ que, obviamente, por el hecho de idearse para representar realidades diferentes y lejanas, fracasan en su acción de definición y contención, se quedan cortos, dejan al descubierto imperfecciones, sobras, incontinencias, restos, señales de una enormidad insumisa que, de inmediato, el ojo occidental traduce en pruebas de incultura, sinónimos barbáricos. Un ejemplo: el poeta neoclásico venezolano Andrés Bello (1780-1865) intenta representar la selva americana ciñéndose a los esquemas pastoriles y bucólicos predicados por las academias y, sin embargo, pronto, el plan escritural se le va al traste, convirtiéndose en otra cosa, pues las melodiosas voces de sus pastores, con sus ridículas 'armonías', se vuelven literalmente inaudibles enfrentadas con el fragoroso estruendo proveniente de la vorágine vegetal. Provocando efectos tragicómicos y malentendidos casi siempre exhilarantes, la naturaleza americana se interpone a la correcta recepción del modelo, obstaculizando la aculturación. La fase siguiente representa la otra cara de la misma moneda: el debate ideológico que fomenta el proceso de emancipación política de las futuras excolonias invierte los términos de la cuestión sin desarmar el constructo,

\footnotetext{
${ }^{9}$ En la breve panorámica que ocupa esta sección del artículo me dejaré guiar por las directrices del brillante ensayo de Rosalba Campra.

10 Según recuerda Albertazzi (2013), de las tres fases que, antropológicamente, darían cuenta del contacto violento entre culturas -según un modelo jerarquizado e impar como el que se produce en los procesos de colonización-, la que acabo de describir correspondería al momento de la copia, al que seguirían el del rechazo del modelo importado y, finalmente, el de la canibalización -llamémosla también transculturación, según la propuesta terminológica de Fernando Ortiz-, eso es: la 'ingestión' del modelo en función de su digestión transgresiva y re-formuladora.
} 
sino simplemente reivindicando la inocencia natural del hombre americano, apropiándose de la etiqueta dentro del marco de un discurso violentamente de-colonial y, de manera igual de maniquea, transformando el libro en algo intrínsecamente europeizante, en un vehículo de corrupción y sofisticación del terruño. Como veremos, será realmente complicado liberarse de las incansables idas y vueltas del cliché, que seguirá arrastrando una secuela de inhibiciones y acondicionamientos hasta bien entrado el siglo XX.

Pasados los furores independentistas, hacia mediados del XIX, por ejemplo, la época de la fundación de las neo-nacidas repúblicas criollas se debate pensativa entre europeísmo y autoctonía; quizás incluso, ante la urgencia de emprender triunfalmente el camino del progreso, tiende a prevalecer la opción de sacrificar una parte fundamental -la más fundamentalmente americana-, se escoge dejar atrás la parte barbárica, la cuota natural, de un continente que, para estar al paso con la modernidad, tiene que ocultar su corazón de tinieblas y apostar por lo importado, elegir la máscara. Las cosas empiezan a cambiar con la década de los Treinta y una serie de narraciones programáticamente regionalistas en las que, como un manifiesto, se merecen el primer plano las vastedades exóticas todavía sin conquistar, donde, de manera emblemática, se enquistan una serie de conflictos auténticamente americanos, intransferibles, propios de un conjunto humano diferente: la así llamada novela de la tierra -que se irá articulando, según el panorama geográfico escogido, en novela de la selva, novela del llano, de la pampa etc.- gira indefectiblemente alrededor de un único inmenso personaje, el paisaje indomable y hechicero, que parece haber dejado de ser intrínsecamente negativo (o positivo) pare ser sencillamente americano, patrimonio regional, nacional y, muy especialmente, continental, materia narrativa por fin original que, sin embargo, en novelas como Doña Bárbara de Rómulo Gallegos o Don Segundo Sombra de Ricardo Güiraldes, sigue tratándose según los esquemas importados de la novela naturalista europea que impone, entre otras cosas, un determinismo implacable y condicionante que deja bien poco margen de actuación a personajes otra vez tipificados ${ }^{11}$.

Es en cambio sólo con el boom que, finalmente, se empieza a trabajar con la percepción americana: este es el nudo que más me interesa explorar porque, como decíamos, constituye el verdadero manantial de donde bebe la divulgación sepulvediana.

Los narradores de los Sesenta representan por primera vez las tierras de la autoctonía desde dentro, de una manera integrada y -digamos- 'holística', tomando prestado de las culturas nativas un nuevo modo de mirarlas: los espacios ancestrales del Continente, convertidos ahora en metas privilegiadas de un corroborante viaje a la semilla de lo humano, a contrapelo, hacia el redescubrimiento de una participación unitaria con la totalidad que pasa preferencialmente por la disolución de la consistencia del sujeto individual, dejarán de ser concebidos como meros apoyos del pensamiento lógico y sometidos a las ansiedades objetivadoras del intérprete, con quien, en cambio, irán entablando una relación simbiótica, transformando sus estructuras cognitivas, obligándolo a abdicar de su prudente distancia crítica, confundiendo, últimamente, la separación epistémica entre sujeto y objeto en un contagio amniótico que, desandando los pasos de la historia y de la evolución, reestablece el espíritu primitivo, reactiva el método mítico. Son estas las claves de un nuevo naturalismo literario

\footnotetext{
11 Jugando con el icónico explicit de La vorágine de José Eustasio Rivera, donde un grupo de cultivados científicos y médicos se pierde en el medio de la gran selva colombiana, en su ensayo dedicado a las modernas tendencias narrativas de las que él también participa en primera persona, el novelista del boom Carlos Fuentes afirma que al personaje novelesco latinoamericano precedente a su generación se lo tragó la selva, aludiendo a ese verdadero -y castrador- prejuicio del espacio.
} 
latinoamericano -uno en donde la fisionomía de las cosas tiende a resbalar con facilidad hacia el ámbito de lo mágico y la observación se desgarra en visión- dentro del cual las culturas originarias le proporcionan al hombre 'civilizado' las herramientas necesarias para moverse, nuevas habilidades adquiridas con toda naturalidad y codificadas como recuerdos de identidad profundos, huellas de una alteridad que, en realidad, hace mucho tiempo, no perteneció cual derecho inajenable.

En Los pasos perdidos de Alejo Carpentier, la descripción de la gran sabana venezolana individúa una frontera insegura, a medio camino entre el tratado de ciencias naturales, la brujería y el repertorio surrealista: "La selva era el mundo de la mentira, de la trampa y del falso semblante; allí todo era disfraz, estratagema, juego de apariencias, metamorfosis. Mundo del lagarto-cohombro, la castaña-erizo, la crisálida-ciempiés, la larva con carne de zanahoria, y el pez eléctrico que fulminaba desde el poso de las linazas" (2004: 297).

¿Quién traza la línea que separa lo posible de lo imposible, la realidad de la maravilla, lo idéntico de lo diferente, en este engañador revoltijo de presagios, larvas, máscaras, incesantes metamorfosis, hibridaciones y mestizajes, todavía empapado en el rocío del amanecer de los tiempos, resistente a toda acción catalogadora? Las categorías del logos no ayudan la lectura, los perfiles de las criaturas son todavía demasiado inciertos, difuminados, movedizos, magmáticos, no han cuajado todavía los confines entre lo vegetal y lo animal, ni entre las diferentes especies, imposible invocar un criterio, inútil discriminar, separar y separarse de esta multitud cambiante. Tan sólo se puede -entroncando con Sepúlveda (1997: 23) - ser "un pelo más de aquel infinito cuerpo verde" "en perpetuo cambio", respirar al unísono, dejarse devorar, apagar la luz del intelecto y adoptar una actitud nocturna, como en el proverbio shuar que el viejo cita en un momento tópico de su aventura: "De día es el hombre y la selva, de noche, el hombre es selva" (47).

De a pequeños pasos nos estamos acercando de vuelta a la cristalización originaria $-\mathrm{y}$ original- de todas esas lujuriosas textualidades primitivamente barrocas, regresamos al íncipit de Cien años de soledad, a la primera, alucinada, visión de Macondo, el pueblo colgante por afuera de todos los mapas geográficos, hundido en un vacío verde esmeralda habitado por "lirios sangrientos" y "salamandras doradas" cerca de una ciénaga inmensa poblada por sirenas "que perdían a los navegantes con el hechizo de sus tetas descomunales" (García Márquez, 1996: 92, 91), "a la orilla de un río de aguas diáfanas" y "piedras pulidas como huevos prehistóricos", cuando el mundo, todavía, "era tan reciente que las cosas carecían de nombre, y para mencionarlas había que señalarlas con el dedo” (79): es el milagro del mundo 'nuevo' -el Nuevo Mundo-, donde la convención cultural todavía no ha dictaminado fronteras y barreras, no ha pronunciado el fatídico 'hasta aquí nomás'. Según Carpentier, el ingenio americano parecería ser el único habilitado para dar cuerpo y sustancia a estas visiones volátiles, por estar naturalmente acostumbrado, gracias a la convivencia directa con la sabiduría "fáustica del indio y del negro" (1976: 99), responsables de su productivo mestizaje, a vivir la maravilla como una de las posibilidades incluidas dentro del perímetro laxo de una realidad "aumentada hasta el delirio" (Vargas Llosa, 1971), pero, reanudando el hilo de nuestras problematizaciones, tampoco aquí, de este lado de la cuestión, estaría demás la pregunta: ¿a quién le pertenece, realmente, esta mirada y de dónde proviene? ¿Podemos considerarla 'naturalmente' nativa? ¿O proviene, más bien, de la cultura de un intelectual educado en Francia, como Carpentier, quien, de regreso de su grand tour europeo, encuentra en el territorio una original variante del visionario irracionalismo de nuestras vanguardias? ¿Y si, en última instancia, el verdadero responsable de estas alucinaciones americanas fuera justamente el viejo conquistador, 
resonando el idiotizado estupor del Descubrimiento en cada una de las fórmulas mágicas de la real-maravilla?

Calibán, definido como un monstruum en su propia isla, se apropia de la definición del forastero, reterritorializándola y convirtiéndola en una bandera...

\section{Exotismos necesarios: mundialización y reposicionamiento político de la real maravilla en Luis Sepúlveda}

Como espero haber demostrado con esta escueta panorámica, citando a Linda Hutcheon, la selva sepulvediana no crece en los árboles, sino proviene de los libros, de una larga e intrincada maraña de tradiciones ramificadas, de un fuego cruzado de representaciones. De hecho, para explorarla, es necesario invocar la convencionalidad de los códigos que -de manera especialmente delicada en América Latina- gestionan las propiedades y pertinencias de lo que se considera 'natura', 'cultura' y 'maravilla', puesto que Sepúlveda, volviendo a activar todas las criticidades vinculadas con el doloroso recorrido de construcción de la identidad americana, funda su pueblo fronterizo, crea su precario idilio tropical, en las arenas movedizas de la más total incertidumbre, definiendo con su escritura una zona de deslices e interferencias donde la civilización invade, sistemáticamente, el territorio de lo absurdo y, por otro lado, la "barbarie" exhibe rasgos sentimentales y melodramáticos que no desentonarían en un salón de té rococó.

Si la ilustración escogida para la portada de la primera edición Tusquets nos sumerge de inmediato en los efectos de estilo de esta fábula exótica, proponiendo una imagen que no podría parecerse más a una imitación de las selvas encantadas de Rousseau el Aduanero -el pintor post-expresionista que constituye una de las referencias fundamentales para el crítico de arte alemán Franz Röh a la hora de acuñar un rótulo, el de Magischer Realismus, que, como sabemos, está destinado a proliferar en América Latina-, el primer capítulo de la novela es un homenaje explícito a García Márquez y a los mecanismos de inversión del punto de vista que, en Cien años de soledad, dan cuenta, en este caso, de la 'maravilla' de la cultura importada, creando episodios hilarantes como el, memorable, del primer contacto de los macondinos con el hielo. En otras palabras, respondiendo a un principio igual y contrario al que provoca que la bellísima Remedios, según va tendiendo la ropa en el patio, quede raptada por una fuerza sobrenatural y ascienda al cielo sin que sus familiares se dejen turbar lo más mínimo -es la provocación de la naturalización de la magia-, los inventos de la ciencia y de la técnica occidental, los ecos de un progreso que no podría parecernos más lejano e inverosímil, se deforman en el texto reproduciendo el extrañamiento del nativo, de manera que su descubrimiento se parece a la aparición de un prodigio $^{12}$.

Aunque de manera mucho menos espectacular que lo que pasa en la novela de Márquez, la llegada a El Idilio del dentista, sus barbáricas sesiones de sanación colectiva celebradas como un ritual chamánico en la plaza del pueblo, sin anestesia, fuera de todo protocolo médicocientífico, en una atmósfera de gran feria multitudinaria en donde, con la misma nonchalance, se suministran fármacos para la presión y lociones para el crecimiento del pelo -y se podría perfectamente hacer pagar la entrada para un espectáculo de cabezas parlantes o telekinesis ${ }^{13}$ nos reconducen a Macondo aludiendo al desenfoque del reconocimiento y a la atenuación del principio de autoridad del progreso occidental y sus 'juguetes' en contextos tan remotos y

\footnotetext{
12 Sobre estos mecanismos, obviamente muy estudiados, véase uno de los ensayos pioneros: Vargas Llosa (1971).

13 Intertextualizo aquí una imagen -la celebérrima del "charlatán del Cabo"-que pertenece a la ensoñación del esclavo Ti Noel en el primer capítulo de El reino de este mundo de Alejo Carpentier.
} 
periféricos, donde los modelos y las indicaciones, muy lejos de obligar, más bien transitan increíbles como alucinaciones tropicales, provocando fenómenos grotescos. En Macondo, de hecho, bajando de su pedestal, los grandes inventos de la modernidad son una entre muchas atracciones de un circo gitano, se introducen, como en un espectáculo de ilusionismo y prestidigitación, por mano de esa especie de científico-brujo que es Melquíades -quizás el más autorizado portador de las marcas de la autorialidad dentro de la novela-, un sabio integral a la manera de los intelectuales de la Edad Media, quien conoce a la perfección los principios de la física pero se pasea por el pueblo en una alfombra voladora. Esta inestabilidad del método, falta de todo tipo de presunción civilizadora, abierta a la negociación de un paradigma mestizo, le convierte en el embajador ideal para entablar, con el Nuevo Mundo, un diálogo entre pares, que rechaza toda polarización rígida y jerarquía, según una fórmula que pone en entredicho la 'realidad' del contacto colonial.

También el dentista sepulvediano -quien llega a este esperpéntico puesto de avanzada de la civilización occidental en la Amazonía con el barco que, como una aparición inconcebible, remonta las corrientes del Nangaritza una vez al mes para abastecer a los lugareños con "provisiones de sal, gas, cerveza [...] aguardiente" (1997: 9) y dispositivos farmacéuticos- es un mediador, no impone o corrige desde lo alto de una hipotética superioridad cultural, sino que ensaya la viabilidad de su arte, midiendo fuerzas con las posibilidades y costumbres del lugar, aceptando el riesgo de la imperfección y el malentendido.

No casualmente, Rubicundo Loachamín es, quizás, el único verdadero amigo de Antonio José Bolívar, que vive aislado, de exilio voluntario y de espaldas a los rituales de la sociabilidad, desencantado con el trato de sus semejantes - los colonos, los aventureros, los buscadores de oro etc., los que depredan la selva sin juicio, dedicándose a construir "la obra maestra del hombre civilizado: el desierto" (28)-, en una choza frugal más allá del perímetro del poblado, hundido en la vorágine vegetal, allí donde la selva madre se disputa el control de la tierra con el gobierno federal ecuatoriano. No casualmente -me parece-, el dentista será su traficante de libros, los únicos artefactos culturales, o debilidades civilizadas, que este desterrado se concede para enfrentar los ataques del astuto "animal de la soledad" (31, la cursiva es mía).

También él, a su manera, es un mediador, tal y como lo fue su progenitor José Arcadio Buendía, el fundador de Macondo, el hombre natural o del mito obsesionado con las novedades importadas por los forasteros, quien sufre en sus propias carnes las punzadas de la insalvable lejanía del mundo americano y, animado por un loco afán de contacto, intenta romper la cáscara del huevo prehistórico procurando abrir una pista que comunique al pueblo con el mundo civilizado. El punto de vista de Bolívar es interno al contexto selvático, como demuestra, por ejemplo, su arenga en defensa de los indios acusados del asesinato del cazador furtivo destrozado por el tigrillo, y también, obviamente, todos los años que pasa en el rancho shuar donde aprende la lengua indígena, participa en sus ceremonias y prueba sus plantas alucinógenas que le hacen sentir "parte innegable de esos lugares en perpetuo cambio" (23). Por otro lado, como decíamos, es también un colono, uno que comparte y respeta los códigos de la selva y, sin embargo, sabe tenerla a raya para no dejarse devorar, en un primer momento, además, odiando con pasión "la región maldita", "el infierno verde" que le arranca la mujer que ama (63), y luego, aprendiendo a tratarla como a un adversario digno, a conocerla para controlarla, incluso prestándose, en un par de ocasiones, a poner su experiencia natural al servicio de un proyecto de exploración y bonificación del que no comparte los intereses ni los modos, ejerciendo, sin embargo, de titubeante mercenario del progreso. En un episodio emblemático de su condición ambivalente, para conseguir los libros (importados) que le tienen 
enganchado con la promesa de rescatar la distancia que lo separa del (espejismo) de la civilización, le roba a la selva unos inocentes 'juguetes naturales', con miras de vender en el mercado de la ciudad más cercana un pobre ejército de loros cautivos y monos enjaulados, trocando formas vivas por una sombra de contacto con esa cultura que, sin haber nunca conocido directamente, le produce una inexplicable nostalgia. En todos los sentidos, Bolívar es una criatura fronteriza, que maneja dos códigos sin llegar a disponer realmente de ninguno de ellos, un personaje obligado a negociar, por fuera y por dentro de sí mismo, entre dos espacios que no le pertenecen, que en ningún caso logra habitar legítimamente.

El conocimiento no garantiza afiliación, menos aún la incómoda sabiduría relacional, el saber intercultural, que es el rasgo que mejor identifica al personaje.

Rechazado por los colonos, que rehúyen de él "mirándolo como a un salvaje" (28), y, a la vez, consciente de ser "como un shuar" sin llegar a ser "uno de ellos" (24), ajeno tanto a la hierática, compacta solidez del mundo indígena como a la rampante cultura de la conquista que está embistiendo sus territorios, perfecto hombre americano, hombre de la soledad, Bolívar -cuyo nombre podría, al fin y al cabo, no ser tan casual- vive metido en una doble ausencia ${ }^{14}$, en una situación de permanente marginalidad, que lo vuelve limítrofe y tangencial tanto con respecto a los códigos de la naturaleza como a los de la cultura, hecho que le impide convertir a ambos en tablas de la ley innegociables.

Es esta condición tambaleante y en suspenso que le vuelve un personaje interesante, infinitamente más que los representantes oficiales de ambos órdenes simbólicos involucrados en el enfrentamiento que le brinda a la novela su argumento, criaturas polarizadas que Sepúlveda dibuja conforme con un molde bastante esquemático: sus indígenas no logran nunca superar el estatuto de sorprendentes curiosidades antropológicas, ciñéndose al patrón del noble salvaje sin matices, sumergidos en una distancia algo museográfica; y las autoridades gubernamentales, con sus insensatas, pueriles reivindicaciones de soberanía sobre "una selva más antigua que todos los Estados" (13), son poco más que microscópicos esperpentos, títeres de zarzuela, como señala el ejemplo del alcalde, un tiranito de cartón piedra que se convierte en una repulsiva babosa cuando en el bosque, dentro del cual se mueve -válgame la inversióncomo un elefante en una cacharrería.

Sin embargo, es con Bolívar que el escritor se gasta sus mejores jugadas, como lo es, sin duda, la afición que le caracteriza, según señala el propio título de la novela. El hecho de construir a su imperfecto héroe primitivo con el vicio del lector empedernido -para más señas, con la pasión de la literatura naïf, los folletines ultra-sentimentales donde las gentes se quieren "de veras" y "sufren mucho", según un gusto que se vería más apropiado en "un viejo marica" (17) - representa un rasgo vistosamente incongruo que, narrativamente, Sepúlveda explota para sanar un equilibrio roto y mantener a su personaje en la frontera, sin concederle asalvajarse del todo, sin consentir que pierda definitivamente el contacto con lo que la selva le ha quitado: la acción (tradicionalmente) civilizadora del amor. Un recurso, entonces, fundamental en el juego de remezcla de los clichés y confusión de las atribuciones de la representación canónica que se ha puesto en marcha.

En plena cacería, sumergidos hasta el cogote en la maravilla perfectamente natural de la selva de noche, tal y como lo haría un jefe indígena con su tribu -claro está, utilizando una materia de índole bastante diferente-, Bolívar entretiene a los demás expedicioneros con el

\footnotetext{
${ }^{14}$ Cito aquí a Abdelmalek Sayad, con el título de un ensayo que se ha convertido en todo un clásico de la sociología de la migración.
} 
relato, totalmente prodigioso en este contexto, de grandes ciudades de piedra, llenas de gente, que durante el invierno se visten de un helado manto blanco. Se renueva, así, el extrañamiento (en el otro sentido de marcha, desde acá hacia el reino de ese mundo), con nuestro héroe en el papel del improvisado cronista indio del Viejo Continente, devolviéndole al ámbito de la 'cultura' el favor del exotismo ${ }^{15}$ :

Al leer acerca de ciudades llamadas París, Londres o Ginebra, tenía que realizar un enorme esfuerzo de concentración para imaginárselas.

$[\ldots]$

Pero, sobre todo le gustaba imaginar la nieve.

También de niño la vio como una piel de cordero puesta a secar en los bordes del volcán Imbabura, y en algunas ocasiones le parecía una extravagancia imperdonable que los personajes de las novelas la pisaran sin preocuparse por si la ensuciaban. (34)

Cuando, más adelante, se trata de visualizar una inverosímil ciudad construida en el agua, teatro de las pasiones bizantinas de dos desgraciados amantes que se van besando furtivamente en una góndola, la sensación de irrealidad llega a tocar cumbres de intensidad intolerables:

[...] estaba molesto ante su incapacidad de imaginar Venecia con los rasgos adjudicados a otras ciudades también descubiertas en novelas.

Al parecer, en Venecia las calles estaban anegadas y, por eso, las gentes precisaban movilizarse en góndolas.

Las góndolas. La palabra 'góndola' consiguió seducirlo finalmente, y pensó en llamar así a su canoa. La Góndola del Nangaritza. (39)

Pasada la tempestad, Próspero y Calibán se disputan el título del más prodigioso.

El único personaje que logra alcanzar la humanísima indecisión identitaria del viejo y que, de hecho, está tallado en la misma madera, es el que está destinado a ser su enemigo mortal, el 'tigrillo furioso' que, de hecho, en el borde de la inverosimilitud, Sepúlveda construye a medio camino entre dos códigos, maravillosamente basculante entre natura y cultura.

Es justamente su comportamiento antinatural, sus acechos imprecisos, su conducta incompatible con el implacable instinto del felino, la "inteligencia refinada" o la "desesperación" que cabe reconocer en la trama que, en efecto, al actuar, la bestia construye, lo que más vistosamente contradice el sistema de las pertinencias. Será ella, desde el otro lado de una frontera cada vez menos eficaz a la hora de contener ordenando significados estables, la que le contará al viejo -y a los lectores- la más conmovedora de las novelas de amor. Como se sugiere en el final, su voz, tan perfectamente articulada, tan alejada del insensato, amenazador estruendo que tradicionalmente se atribuye a la fiera -la voz de la selva responsable de este inédito relato de civilización-, conseguirá quizás amansar a los 'hombres feroces', invirtiendo el rumbo del mito clásico.

Hay un momento de gran intensidad lírica en la descripción de la pelea a muerte que, según un esquema decidido de antemano por un gran titiritero invisible, ve protagonistas a dos

\footnotetext{
15 Esta imagen es muy parecida a la que cierra el relato de Carlos Fuentes titulado "Las dos orillas", uno de los cinco que componen el mosaico de El naranjo, en donde, desandando los pasos de la historia, un ejército náhuatl conquista Europa mientras sus cronistas fabulan un inverosímil aterrizaje en la luna.
} 
adversarios reacios y, en definitiva, tan parecidos. Me refiero al pasaje en el que Bolívar, metido hasta el cogote en la visionaria confusión de la noche vegetal, mojado hasta los huesos por los humores encantados de la real-maravilla, alcanza a entrever, cifrada en los engañosos amagos de la maleza que no para de transformarse junto con todas sus criaturas, la señal de una inestabilidad definitiva. El cazador y su presa, el hombre y la bestia, durante un momento revelador que, enseguida, se escapa, se encuentran sin máscaras y se confunden el uno en el otro:

Frente a él, algo se movía en el aire, en el follaje, sobre la superficie del agua quieta, en el fondo mismo del río. Algo que parecía tener todas las formas, y nutrirse al mismo tiempo de todas ellas. Cambiaba incesantemente, sin permitir que los ojos alucinados se acostumbrasen a una. De pronto asumía el volumen de un papagayo, pasaba a ser un bagre guacamayo saltando con la boca abierta y se tragaba la luna, y al caer al agua lo hacía con la brutalidad de una quebrantahuesos desplomándose sobre un hombre. Ese algo carecía de forma precisa, definible, y tomara lo que tomara siempre permanecían en él los inalterables brillantes ojos amarillos.

—Es tu propia muerte disfrazándose para sorprenderte. (61)

Después de un vertiginoso carrusel de metamorfosis, la indomable alteridad de tantas representaciones -la selva devoradora, némesis de todas las culturas-, se convierte en el último rostro, el rostro definitivo, o sea, se vuelve espejo, superficie reflectante que nos restituye nuestra propia imagen. Cultura y natura -cómplices los códigos de la maravilla- se reconocen dobles idénticos, ilusorias máscaras polémicas de un discurso compartido.

Provista de una inusitada fuerza narrativa, a ratos insufriblemente ingenua y, sin embargo, adictiva, exactamente como una de las novelitas rosas que el viejo Bolívar no puede evitar devorar -y de los que nuestro libro, más o menos conscientemente, da una versión invertida, volviendo a embaucar al lector occidental con los vidrios de colores de una selva que tan encantada y exótica no había sido desde los tiempos de Cien años de soledad-, la primera novela de Sepúlveda representa un ejercicio, culturalmente urgente, sobre la inestabilidad y la relatividad de los códigos que dibujan nuestras fronteras. En sus páginas, la América Latina globalizada y uniforme de la 'generación $\mathrm{McO}_{\mathrm{c}} \mathrm{no}$ ', vuelve a ser, en el mejor de los sentidos posibles, un mundo nuevo donde, escuchando una antigua cantaleta, las cosas todavía son tan recientes... que es posible de-categorizarlas, moverlas de sus posiciones fijas, volviendo a pactar sus significados y alcances simbólicos, así como, por otro lado, es necesario seguir haciendo con nuestros valores, nuestras bases cognitivas, los parámetros de lo que consideramos 'civilizado', los confines de 'nuestro mundo'.

\section{BIBLIOGRAFÍA:}

AÍNSA, Fernando (1986). Identidad cultural de Iberoamérica en su narrativa. Madrid: Gredos

AÍNSA, Fernando (2012). Palabras nómadas. Nueva cartografía de la pertinencia. Madrid/Frankfurt. Iberoamericana/Vervuert.

ALBERTAZZI, Silvia (2013). La letteratura postcoloniale. Dall'Impero alla World Literature. Roma: Carocci.

BECERRA, Edoardo (2008). ¿Qué hacemos con el abuelo? La materia del deseo de Edmundo Paz Soldán. En Jesús MONTOYA JUÁREZ \& Ángel ESTÉBAN (eds.), Entre lo 
local y lo global. La narrativa latinoamericana en el cambio de siglo (1990-2006). Madrid/Frankfurt: Iberoamericana/Vervuert.

BENSA, Tatiana (2005). Identidad Latinoamericana en la literatura del boom. Revista de estudios iberoamericanos, 2, 87-92.

CALABRESE, Stefano (2015). Anatomia del bestseller. Milano: Laterza.

CAMPRA, Rosalba (1998). América Latina: la identidad y la máscara. Barcelona: Siglo XXI.

CARPENTIER, Alejo (1976). De lo real maravilloso americano. En Tientos y diferencias, Buenos Aires: Calicanto, 83-99.

CARPENTIER, Alejo (2004). El reino de este mundo/Los pasos perdidos. Barcelona: Siglo XXI.

CESERANI, Remo (1997). Raccontare il postmoderno. Torino: Bollati Boringhieri.

ERCOLINO, S. (2015). Il romanzo massimalista. Roma: Bompiani.

FAVA, F. (2012). Urbanismo magico? O urbanismo McIntosh? La città ispanoamericana tra Macondo e Santa Teresa. Orillas, 1, 1-16.

FUENTES, Carlos (1969). La nueva novela hispanoamericana. México DF: Cuadernos de Joaquín Mortiz.

FUENTES, Carlos (2008). El naranjo. Madrid: Alfaguara.

FUGUET, Alberto \& GÓMEZ, Sergio (Eds.) (1996). McOndo. Barcelona: Random House.

GARCÍA MÁRQUEZ, Gabriel (1996). Cien años de soledad. Madrid: Cátedra.

GARCÍA MÁRQUEZ, Gabriel (2014). La soledad de América Latina. Discurso de aceptación del Premio Nobel 1982. Educere, 18 (Enero-Abril). Disponible en línea: http:/ / www.redalyc.org/articulo.oa?id=35631103020. [Última consulta: 12 de agosto de 2019].

GRUZINSKY, Serge (1991). La colonización de lo imaginario. México DF: Fondo de Cultura Económica.

HUTCHEON, Linda (1988). A Poetics of Postmodernism. London: Routledge.

LEÓN DE HAZERA, Lydia (1971). La novela de la selva hispanoamericana. Bogotá: Instituto Caro y Cuervo.

MALAVER RODRÍGUEZ, Rodrigo (2001). La selva imaginada. Una relectura crítica de El viejo que leía novelas de amor de Luis Sepúlveda. Cuadernos de literatura, 7 (13.14), 31-44.

MONTOYA JUÁREZ, Jesús \& ESTÉBAN, Ángel (Eds.). (2008). Entre lo local y lo global. La narrativa latinoamericana en el cambio de siglo (1990-2006). Madrid/Frankfurt: Iberoamericana/Vervuert.

NOGUEROL, Francisca (2008). Narrar sin fronteras. En Jesús MONTOYA JUÁREZ \& Ángel ESTÉBAN (eds.), Entre lo local y lo global. La narrativa latinoamericana en el cambio de siglo (1990-2006). Madrid/Frankfurt: Iberoamericana/Vervuert.

OVIEDO, José Miguel (1969). Macondo: un territorio mágico y americano. En Nueve asedios a García Márquez. Santiago de Chile: Editorial Universitaria.

PALAVERSICH, Diana (2005). De Macondo a McOndo. Senderos de la postmodernidad latinoamericana. México DF: Plaza y Valdés.

ROH, Franz (1927). Realismo mágico. Revista de Occidente, $V$, XLVIII.

RÖSSNER, Michael (1997). De la búsqueda de la propia identidad a la deconstrucción de la historia europea. En Karl KOHUT (ed.), La invención del pasado. La novela histórica en el marco de la postmodernidad. Madrid/Frankfurt: Iberoamericana/Vervuert.

SAID, Edward (2003). Orientalism. London: Penguin.

SAYAD, Abdelmalek (2011). La doble ausencia: de las ilusiones del emigrado a los padecimientos del inmigrado. Madrid: Anthropos.

SEPÚLVEDA, Luis (1997). Un viejo que leía novelas de amor (35ª ed.). Barcelona: Tusquets. 
AIC

TODOROV, Tzvetan (2013). La conquista de América: el problema del otro. Barcelona: Siglo XXI.

VARGAS LLOSA, Mario (1971). Gabriel García Márquez. Historia de un deicidio. Lima: Barral.

VOLPI, Jorge (2009). El insomnio de Bolivar. Barcelona: Debate. 
